\title{
Article \\ Additive Manufacturing for Effective Smart Structures: The Idea of 6D Printing
}

\author{
Stelios K. Georgantzinos ${ }^{1, *(\mathbb{D})}$, Georgios I. Giannopoulos ${ }^{2} \mathbb{D}$ and Panteleimon A. Bakalis ${ }^{3}(\mathbb{D}$ \\ 1 Department of Aerospace Science and Technology, National and Kapodistrian University of Athens, \\ 34400 Psachna, Greece \\ 2 Department of Mechanical Engineering, University of Peloponnese, 1 Megalou Alexandrou Street, \\ 26334 Patras, Greece; ggiannopoulos@uop.gr \\ 3 General Department, National and Kapodistrian University of Athens, 34400 Psachna, Greece; \\ pbakalis@uoa.gr \\ * Correspondence: sgeor@uoa.gr
}

Citation: Georgantzinos, S.K.; Giannopoulos, G.I.; Bakalis, P.A. Additive Manufacturing for Effective Smart Structures: The Idea of 6D Printing. J. Compos. Sci. 2021, 5, 119 https://doi.org/10.3390/jcs5050119

Academic Editors:

Francesco Tornabene and

Thanasis Triantafillou

Received: 8 April 2021

Accepted: 29 April 2021

Published: 1 May 2021

Publisher's Note: MDPI stays neutral with regard to jurisdictional claims in published maps and institutional affiliations.

Copyright: (c) 2021 by the authors. Licensee MDPI, Basel, Switzerland. This article is an open access article distributed under the terms and conditions of the Creative Commons Attribution (CC BY) license (https:// creativecommons.org/licenses/by/ $4.0 /)$.

\begin{abstract}
This paper aims to establish six-dimensional (6D) printing as a new branch of additive manufacturing investigating its benefits, advantages as well as possible limitations concerning the design and manufacturing of effective smart structures. The concept of $6 \mathrm{D}$ printing, to the authors' best knowledge, is introduced for the first time. The new method combines the four-dimensional (4D) and five-dimensional (5D) printing techniques. This means that the printing process is going to use five degrees of freedom for creating the final object while the final produced material component will be a smart/intelligent one (i.e., will be capable of changing its shape or properties due to its interaction with an environmental stimulus). A 6D printed structure can be stronger and more effective than a corresponding $4 \mathrm{D}$ printed structure, can be manufactured using less material, can perform movements by being exposed to an external stimulus through an interaction mechanism, and it may learn how to reconfigure itself suitably, based on predictions via mathematical modeling and simulations.
\end{abstract}

Keywords: additive manufacturing; 6D printing; 4D printing; 3D printing; smart materials; nanocomposites

\section{Introduction}

Additive manufacturing (AM) or 3D printing, discovered in the 1980s as a rapid prototyping method and is now considered as a manufacturing process, practically in the same way as the conventional manufacturing processes. AM has generated an impact in all industry areas, including aerospace [1,2], automobile [3], construction [4], medical and military [5]. It offers flexibility in the product design process, a considerable reduction in material consumption, as well as makes product personalization affordable [6]. ASTM International categorizes AM processes in seven groups [7] (i.e., material extrusion (e.g., fused deposition modeling-FDM), powder bed fusion, vat photopolymerization (stereolithography-SLA), material jetting (e.g., PolyJet), sheet lamination, directed energy deposition, and binder jetting), each typified by the principle according to which matter is formed.

In terms of advances in technologies and applications concerning 3D printing, one of the extraordinary reported developments so far is $4 \mathrm{D}$ printing in which $3 \mathrm{D}$ printing technology is combined with smart materials (SMs) to produce structures that change shape over time [8-10]. More specifically, in 4D printing, the developed 3D object can self-transform or respond to external stimuli over time [11]. In other words, time could be considered as the 4 th printing dimension. Here, time is not utilized to describe for how long the object is printed but expresses the fact that it can continue to evolve [12,13] after being printed or even the ability to self-regenerate [14]. 4D printing is expected to play a crucial 
role in future designs due to its obvious advantages. For instance, 4D printing may allow scientists to develop, micro/nano-actuators and/or smart devices, without additional equipment, i.e., wires, motors, and batteries. Applications of $4 \mathrm{D}$ printing have been already referred to in several fields. Characteristically, 4D printing has already been successfully applied for manufacturing various products including structures with multi-directional properties [15], soft actuators [16], and others.

The production of products with material intelligence (i.e., SMs), via the 4D printing technique, requires the achievement of the self-transformation skill. The final printed smart objects should possess expandable, adaptable, and/or deformable characteristics in response to an employed stimulus (i.e., temperature, humidity, or solvents), as well as $\mathrm{pH}$ or light [17]. The materials utilized for structure evolution exhibit an abundance of properties (i.e., self-healing [18], self-assembly [19], self-sensing, decision making, and self-adaptability) [20]. Shape morphing following printing is the key feature of 4D printing. Shape changes in $4 \mathrm{D}$ printed structures can be caused by various external stimuli, to produce folding, expansion, or shrinkage of the printed objects. These evolutions are characterized by different behaviors for objects comprised of one SM and bilayer structures with different properties and inhomogeneity [21,22].

If a 3D printed object, beyond its morphing into a new shape (4D printing), can further change its function, this transformation could be called, also as 5D printing. Nevertheless, a comprehensive definition of $4 \mathrm{D}$ printing is more appropriate to include the evolution of the 3D printed structure concerning changes in shape, property, as well as in functionality. On the other hand, " $5 \mathrm{D}$ printing" is more commonly referred to as a name for five-axis AM $[23,24]$. The term " $5 \mathrm{D}$ " is used to describe the five-axis printing method, firstly proposed by Mitsubishi Electric Research Laboratories (MERL), which is accomplished by the utilization of a print bed that rocks back and forth on two-axis, creating the fourth and fifth processing axis [23]. The competitive advantage of 5D printing compared with 3D printing is that it can produce stronger objects using less material [24].

Here, to our best knowledge, an attempt will be made for the first time in the open literature to introduce the concept of 6D printing followed by the necessary theoretical background, potential areas of application, and possible arisen benefits. The idea is simple, novel, worth researching, and can easily be described as follows: A 6D printed structure could be regarded as a child born from the marriage between a five-axis printer of FDM technology and SMs. It can be stronger than a corresponding $4 \mathrm{D}$ printed structure, can be manufactured using less material, can change shape due to an external stimulus via an interaction mechanism, while its structural quality and intelligence may be improved by introducing computational optimization methods and simulations.

\section{The Ground Idea}

Today, the benefits of 3D printing are well established: Design freedom, part consolidation, no tooling necessary, just-in-time inventory, faster production, easily accessible, tangible design, cost-effectiveness, creative designs, unlimited shapes and geometry, variety of raw materials, less waste production, risk reduction and others [25]. From an engineer's point of view, the list of practical advantages is boundless. Taking into account all of these benefits, one would consider that 3D printing would be a very common manufacturing procedure in our times. However, this is not true: The industry is struggling to incorporate efficient technology into its production. However, AM is still less than $2 \%$ of the entire manufacturing market. This is due to the fact that some challenges do not allow the extensive adoption of the specific AM. Common problems associated with 3D printing are imperfections in the final product, post-processing requirements, longer production timelines, limitation to ordinary material components, etc.

Any current limitation associated with the 3D printing process is inevitably transferred to the $4 \mathrm{D}$ Printing technology. The 4D restrictions may be divided into two main categories. The first category is related to the manufacturing process itself, while the second one has to do with the functionality, characteristics, and capabilities of the final smart structure. 
Regarding the manufacturing limitations, the need for supporting material as well as the post-process requirement for its removal should be highlighted. In addition, the lack of additional printing degrees of freedom, evidently, leads to the need for extended processing routes and, thus, to longer processing times, while the achievable structural complexity and coherence, that governs the SM strength, is rather restricted. Finally, analogous limitations arise regarding the SM stimulus-response capabilities due to the lack of the extra printing directions. It should be noted that despite the fact the $4 \mathrm{D}$ printing may allow the production of SM components with a complex orientation by using more convoluted programming, does not have the high manufacturing flexibility regarding the layer-by-layer orientation that is offered by the 6D printing method.

To improve and optimize some features and aspects of the AM, a novel concept is proposed here. The main objective of the idea is the scientific establishment of the six-dimensional (6D) printing concept, which is schematically explained in Figure 1.

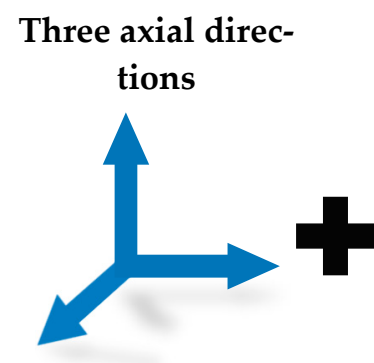

$3 \mathrm{D}$
Two rotational degrees of freedom

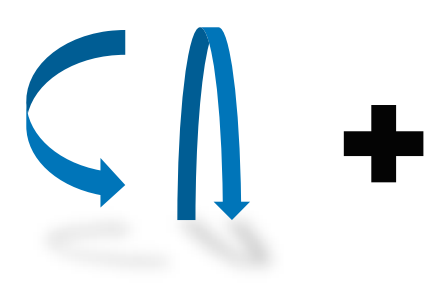

2D
One dimension of

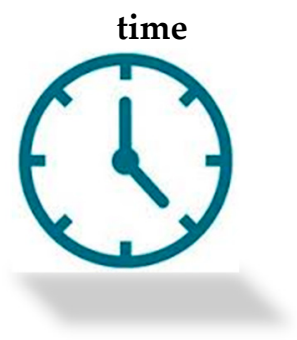

1D
Effective smart structure

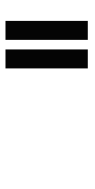

6D Printing

Figure 1. The 6D Printing method: Dimensionality clarification.

The 4D and 5D printing concepts should be clarified beforehand in order to enlighten the aim of the current exploration.

The 4D printing technology [26] is grounded on the 3D one, nonetheless, additionally requires the use of stimulus and stimulus-responsive raw materials. Thus, such a manufacturing process leads to the production of the famous SMs [27]. In other words, the alteration of the 4th dimension of the part is indirectly achieved via a stimulus condition which is applied after its printing finalization. On the other hand, the 5D technology [26] refers to common, non-intelligent final material component products, which; however, are manufactured by the use of a five-axis printing technique, instead of the three-axis one used in 3D printing, a fact that enables the process of objects in multiple dimensions.

The concept of $6 \mathrm{D}$ printing, to the authors' best knowledge, is introduced for the first time. The new method combines the $4 \mathrm{D}$ and the 5D printing techniques. This means that the printing process is going to use five degrees of freedom for creating the final object while the final produced material component will be a smart/intelligent one (i.e., will be capable of changing its shape due to its interaction with an environmental stimulus).

The expected arisen benefit due to the realization of such a novel manufacturing process is, first and above all, the capability of printing structures that exhibit intelligent behavior that has unique "response to stimulus" characteristics due to the arisen distinctive structural features. The new multi-axis printing capabilities are expected to lead to a new family of SMs which will also be more easily manufactured to tighter tolerances and specifications. Apart from achieving a unique material intelligence by incorporating two more printing axis, the proposed technology is additionally expected to be highly capable of producing stronger products, of better quality at minimized processing times.

Finally, yet importantly, the method may support effectively not only single-phase polymers but also nano-reinforced polymers [28] as raw materials, in a more specialized manner. The use of suitable nano-inclusions and nano-reinforcements [29] is expected to 
provide even more specialized final properties of the final 6D printed SM. The addition of nanomaterials to the polymeric basic raw material increases the complexity of the method design (i.e., the calibration for the printer and the whole printing setup as well as the computational modeling and simulation predictions required for the proper design of the whole manufacturing technique and final product) [30].

Overall, this work aims to highlight the benefits from the establishment of a new field in prosthetic technology, which can give new possibilities and designs whereas it has not yet been introduced in the literature. The presented concept needs to be distinguished from existing available technologies, as it will not only offer more degrees of freedom in construction and make manufacturing more efficient in terms of material use and production time but can give new designs and novel smart functionalities, which are difficult to be realized via the existing additive technology. The capabilities which arise from the idea of the $6 \mathrm{D}$ Printing method are inherently based on the printing production processes and its settings and not just on the properties of the material. According to the proposed definition, the single intelligence or multiple intelligences of the SM products that lead to the extra dimension (i.e., the multidirectional evolution or simultaneous change of several material attributes in time due to excitation) are all integrated into one dimension, avoiding, in this manner, any possible definition vagueness. To better differentiate each category of additive manufacturing over the proposed one, Table 1 is presented which contains the main aspects and characteristics of each relevant technique. Note that, on the whole, the proposed idea aims at improving the quality, programmability, and adjustability of the dynamic after-print multi-intelligent response of the SM object. The main advantage of the method is the fact that enables the printing in more directions and along more complicated or even curved paths, thus, leading to more well-designed products regarding both the achieved structural integrity as well as the level of intelligence. Finally, the 6D printing method accompanied with an appropriate setup may allow the use of less raw material and may simultaneously provide shorter processing times due to its inherent processing flexibility.

Table 1. Categories of additive manufacturing techniques with their basic features.

\begin{tabular}{|c|c|c|c|}
\hline Addictive Manufacturing & Required Equipment & Basic Characteristics & Limitations \\
\hline 3D Printing & 3D printers & $\begin{array}{l}\text { Layer by layer development } \\
\text { in the vertical axis }\end{array}$ & $\begin{array}{l}\text { Inflexibility on the layer } \\
\text { orientationProduct with no } \\
\text { intelligence }\end{array}$ \\
\hline 4D Printing & $\begin{array}{l}\text { 3D printers } \\
\text { Raw material with } \\
\text { intelligences }\end{array}$ & $\begin{array}{l}\text { Creation of Smart Materials } \\
\text { (SM) Products }\end{array}$ & $\begin{array}{l}\text { Limits regarding the layer } \\
\text { orientation } \\
\text { Intelligences of restricted } \\
\text { programmability and strong } \\
\text { directivity }\end{array}$ \\
\hline 5D Printing & $5 \mathrm{D}$ printers or robotic arms & $\begin{array}{l}\text { Layering in every direction } \\
\text { Less material and process time }\end{array}$ & $\begin{array}{c}\text { Product with no intelligence } \\
\text { Higher setup cost }\end{array}$ \\
\hline 6D Printing & $\begin{array}{l}\text { 5D printers or robotic arms } \\
\text { Raw material with } \\
\text { intelligences }\end{array}$ & $\begin{array}{l}\text { Layering in every direction } \\
\text { Less material and process } \\
\text { time Creation of SM Products } \\
\text { of flexible and adjustable } \\
\text { programmability }\end{array}$ & $\begin{array}{c}\text { Additional calibration and need } \\
\text { for standardization } \\
\text { Higher setup cost }\end{array}$ \\
\hline
\end{tabular}

The setup cost regarding the 6D printing process is expected to be high. However, the positive economic influence of adopting the proposed method is highly dependent on the production lot size and the level of integrated automation. The more massive the production via $6 \mathrm{D}$ printing, the higher the overall cost reduction in comparison with the $4 \mathrm{D}$ printing method, due to the minimization of the raw material loss. 


\section{Methodology}

The $6 \mathrm{D}$ printing process is briefly outlined diagrammatically in the flow chart of Figure 2. Each basic step of this process corresponds to the objectives that are presented in this section.

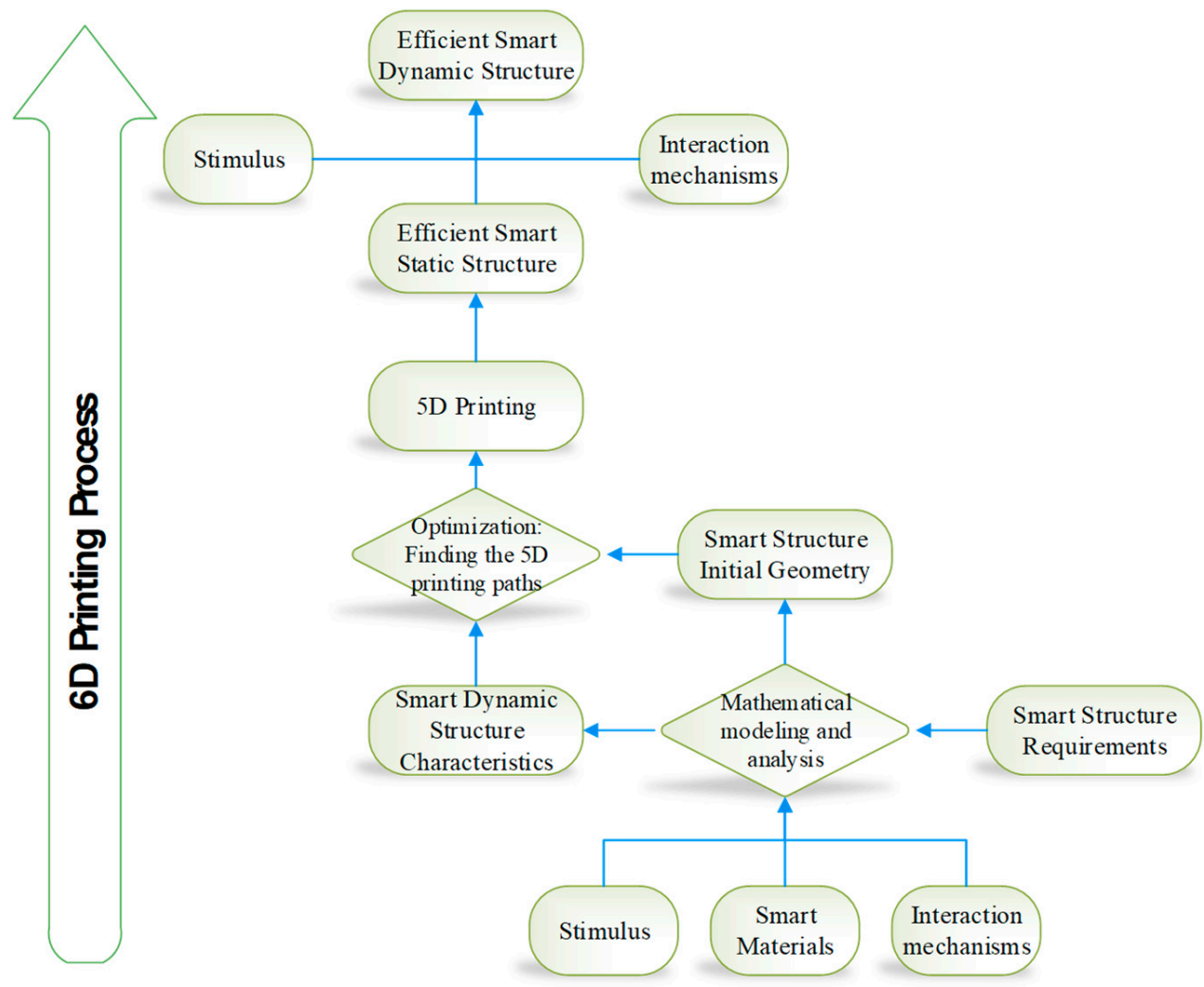

Figure 2. The concept of $6 \mathrm{D}$ printing.

\subsection{Database of SMs—Stimuli Interaction Mechanisms}

One category of printing materials that is under the spotlight in the last years is the SMs [31]. When a product is printed by using suitable raw materials, it may be transformed into an alternative structure that is intelligently sensitive to the influence of external energy that is input in the form of pressure, temperature, electric field, magnetic field, light, or other environmental stimuli. As a first step, for the establishment of the proposed process, an extended literature review is required regarding all the existing SMs and their properties, stimuli, and interaction mechanisms in order to identify the most suitable SMs for the application of the 6D AM.

Further investigations should be conducted to identify all the available polymers [32] as well as nano-reinforced polymers [33] which could be successfully melted and processed by the headed end of the $5 \mathrm{D}$ printer extruder, thus used as candidate printing raw materials. The development of a database concerning the aforementioned relevant raw material records may allow the development of simple and effective computational and analytical methods, which are originally required for modeling and designing the final products as well as finding the ideal manufacturing procedures.

\subsection{Multi-Scale Modeling and Analysis of SMs and Structures}

The final structure of the investigated printed SMs will be accomplished (a) after depositing small drops of melted polymeric media, which on occasion will be nanoreinforced, layer-by-layer; and (b) after cooling the printed smart component at room temperature. Furthermore, it is evident that the response of the SMs by a stimulus, such as environmental temperature, stress, strain, electrical current, magnetic field, etc., is 
strongly dependent not only on the final formation and molecular structure of the involved polymeric chains but also by the position and physical properties of the nano-reinforcement alone. Moreover, the investigation and accurate representation of the molecular kinetics, the relevant glass transition phenomena, the interphase interactions, the electrostatic and vdW forces is of high importance for developing the necessary stimulus interaction mechanisms and; therefore, for selecting the after-print SM proper design.

At the stage of the product and process optimal design, extensive comparisons between the novel $6 \mathrm{D}$ and the $4 \mathrm{D}$ printing techniques should initially be made at a theoretical level, to reach rigid conclusions about the superiority of the proposed process. Given the nanoscale significant effects governing the adopted smart materials, special formulations based on the combination of the molecular dynamics (MD) [34] and the finite element method (FEM) [35,36] must be developed to simulate the final printed material components, in an effort evaluate, control and characterize the design aspects and parameters of the investigated products. Generally, the effects at the nanoscale of both the polymeric chains as well as the involved nano-fillers under the stimulus conditions require the combination of both atomistic as well as continuum numerical techniques. Thus, appropriate MD, FEM, as well as combined multi-scale computational methods [37] should be introduced, developed, validated, and parametrically applied in order to capture the SM behavior at the nano, micro, and physical scale. The aim is the efficient modeling and simulation of the final printed products under the stimulus conditions, with low computational cost and high accuracy.

\subsection{Optimal Paths of 5D Printed Smart Structures}

In $5 \mathrm{D}$ printing, the printed part moves and rotates while the printer head is printing, so as for the printing to undertake the curve path of the part being printed rather than moving through a flat layer as in the case of $3 \mathrm{D}$ printers. This is expected to provide stronger structures using less material [35] in comparison with classical 3D printing. Besides that, both $3 \mathrm{D}$ and $5 \mathrm{D}$ printing techniques use the same technologies such as the input of 3D $\mathrm{CAD}$ files and the same printing materials.

The evaluation and calibration of the process require extensive experimental investigation. Numerous parts using different arrangements and printing paths should be produced and then tested. The experimental examination should be realized by using both standard $3 \mathrm{D}$ printing equipment as well as a five-axis printer capable of processing a variety of pure and nano-reinforced raw materials at different temperature levels.

In the conventional 3D printing process, between the CAD model that expresses the final design of the structure and the 3D printer, there is the 3D printing slicing software (slicer) essentially acting as the middleman. This software slices the 3D CAD model into 2.5D layers along the transverse axis (z-axis), generating the optimal paths of the extruder in the FDM technology through g-code. Settings in parameters like infill pattern, infill density, layer height, etc. can affect the behavior of the printed structure. Given that the printing process in a $5 \mathrm{D}$ printer can be performed in more axes, the presence of more parameters and combinations of parameters is inevitable. For example, the infill pattern and density as well as the presence of multiple materials can be developed in more directions than in 3D printing. The relations between the printing parameters and the resulting physical properties (mass, tensile strength, glass temperature, electrical conductivity, etc.) may influence the SM behavior, and, thus, should be systematically examined using standardized samples and a bottom-up approach, starting from simple to more complex geometries. The behaviors must be recorded, and semi-analytical equations may be extracted performing appropriate regression analysis. By determining the optimization problem, defining the objective function, variables, constraints, etc., as well as using multi-criteria analysis and/or artificial intelligence algorithms, optimum solutions could be obtained. The goal is to find the best process parameters that lead to increased SM quality as well as high productivity. 


\subsection{Efficient Smart Structures in Action}

At the final stage, the assessment of the $6 \mathrm{D}$ printing method should focus on the achieved intelligence of the printed objects. Firstly, the experimental measurements should be conducted in order to determine the response of the $6 \mathrm{D}$ printed part under the action of static stimulus conditions. The efficiency and accuracy of the intelligent $6 \mathrm{D}$ printed objects in changing shape or/and properties under the corresponding stimulus is to be evaluated. Obviously, the accurate response and quick reaction to the stimulus are strongly dependent on the structural quality of the final part and, consequently, related to the followed $6 \mathrm{D}$ printing process. Thus, carefully designed after-print experiments and measurements may give valuable information for further improvements. After validating the proposed manufacturing procedure for producing SMs with an excellent response under a static interaction with the environment, the investigation should proceed to the characterization of the dynamic stimuli-response of the 6D printed SMs.

\section{Potential Benchmarks}

For convenience, the performance of the $6 \mathrm{D}$ concept should initially be examined through simple problems and applications, some of which are proposed in this section.

The investigation may focus on specific component geometries and material constituents. In order to evaluate the benefits of the $6 \mathrm{D}$ printing over the $4 \mathrm{D}$ one, an experimental investigation may be performed regarding the overall strength, surface quality, stimulus-response, and production efficiency of the final produced SM components (parts). The final specimens should be manufactured via both $6 \mathrm{D}$ and $4 \mathrm{D}$ methods and the processing times as well as the achieved physical properties may be set into contrast through statistical methods in order to reach confident conclusions.

The expected superiority of the $6 \mathrm{D}$ printing may be demonstrated via the indicative example and graphical comparison illustrated in Figure 3. The left and right material component is manufactured by using the $4 \mathrm{D}$ and the proposed $6 \mathrm{D}$ printing method, respectively, via the use of a combination of layers made of different polymer media, for example, Polylactic acid (PLA) layers $[9,10]$ may be combined in an alternating manner with a different polymeric medium such as thermoplastic polyurethane (TPU). Here, the glass transition temperature ( $\mathrm{Tg}$ ) difference, causing internal residual stress mismatches, will be the key. Both flat specimens are expected to bend into a U-shape when environmental temperatures become higher than $\mathrm{Tg}$. It should be mentioned that some or all of the plastic layers may be reinforced with nanomaterials such as graphene nanoribbons [29], using appropriate row material available in the international market.
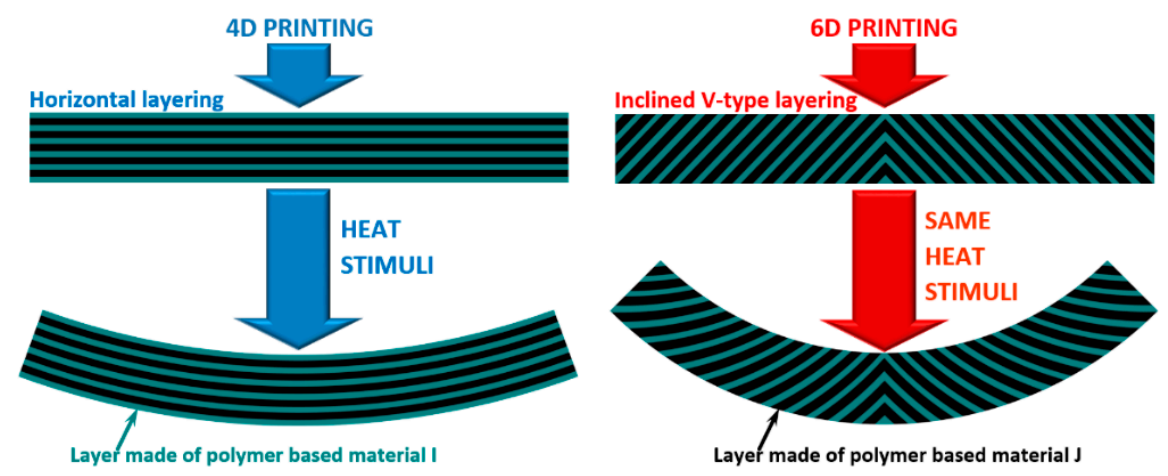

Figure 3. An indicative comparison between $4 \mathrm{D}$ and $6 \mathrm{D}$ printing: Bending deformation of a printed component is increased due to a heat stimulus when the proposed $6 \mathrm{D}$ printing process is utilized instead of the $4 \mathrm{D}$ one.

Since both investigated 4D and 6D printed SMs are composed of alternating layers of two different polymeric materials, they evidently will obtain bending deformations under the stimulus of heat/temperature [9]. The left specimen which is manufactured via 
3D printing only consists of flat polymeric layers. In contrast, the right product contains V-type layering which is possible only by the use of $6 \mathrm{D}$ printing. Thus, it becomes evident that for this specimen, a more intensive, efficient, and controllable self-bending behavior is expected. Furthermore, utilizing the proper processing parameters, the $6 \mathrm{D}$ printing may require less material, lower manufacturing time for similar results.

Another potential application may be inspired by the field of magneto-sensitive smart materials, also known as magnetorheological materials. Such materials are a class of smart composites prepared by dispersing nanometer- or micrometer-sized ferromagnetic fillers into different matrix phases [38]. Their rheological properties and deformations may be effectively controlled by an external magnetic field. A possible relevant $6 \mathrm{D}$ printed product is illustrated in Figure 4. As depicted, the specimen has a complex structure consisting of inclined layers made of pure polymer and nanoreinforced polymer. Each nanocomposite layer is constituted by a polymer matrix material filled with magnetic nanoparticles. Due to the application of a strong magnetic field and because of the aforementioned structural attributes achieved via $6 \mathrm{D}$ printing, the specimen becomes highly stretched along its one direction because of the arisen common orientation of the nanoparticles as well as the shape of layering. In addition, taking into advantage the two extra available fabrication axes, it is expected that the intelligence of the final products, apart from enhanced will also be more controllable to meet the requirements of the manufacturer. Finally, the process setup may be adjusted to produce more deformable but simultaneously stronger smart material components.

LACK OF EXTERNAL MAGENTIC FIELD
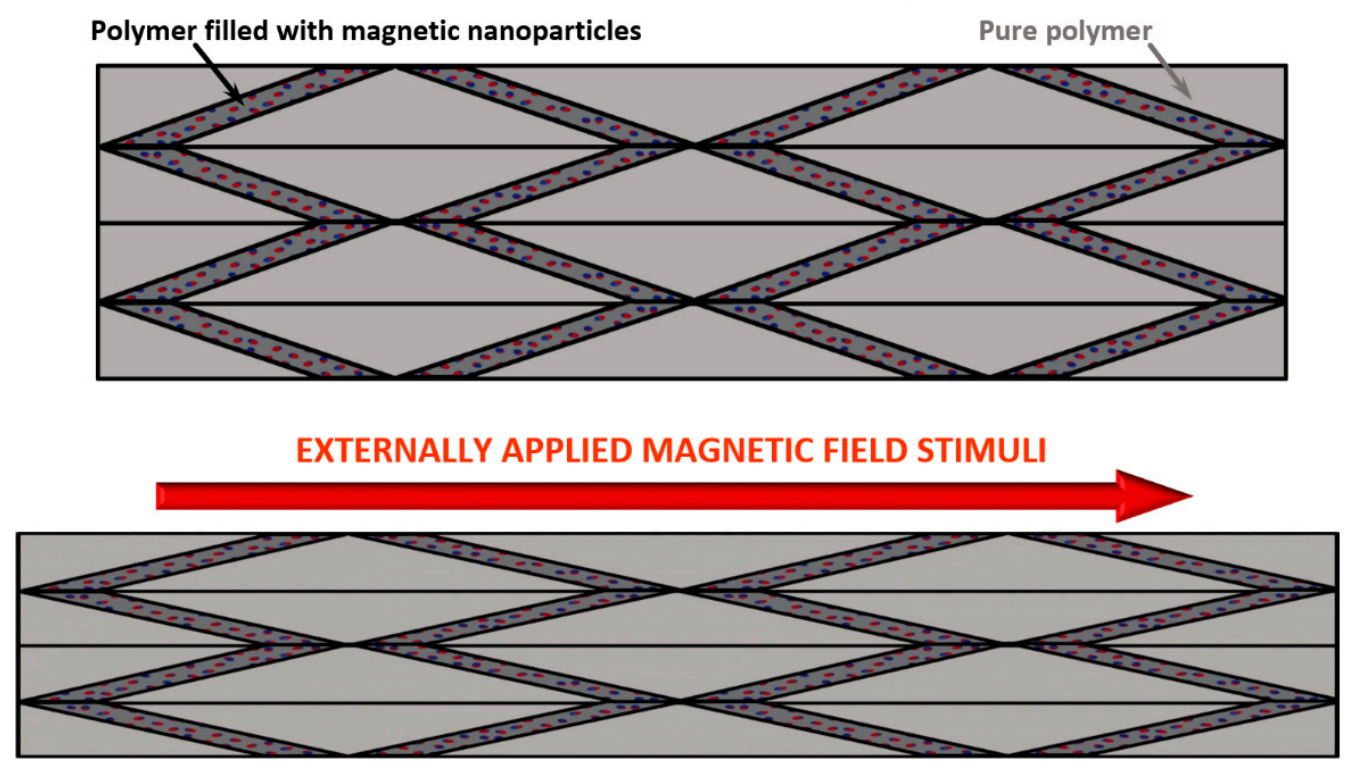

Figure 4. An indicative application of 6D printing. The inclined complex layering by using combinations of pure and nano-reinforced polymeric layers allows intensive response under the action of a magnetic stimulus.

\section{The Technological Impact}

As it was already mentioned, the proposed manufacturing procedure combines the 5D printing concept (which involves the motion of the printing head along with the rotation of the print bed at defined angles) with the $4 \mathrm{DP}$ (which leads to SMs modified with respect to the time) into a new concept called 6D printing. Evidently, the developed AM process will lead to the creation of a new generation of advanced SMs that can also contain nanoparticles in their structure. It is evident, that such a development in the field of multi-dimensional printing technology will drastically boost the whole societal impact of AM [30]. 
First of all, the new method is expected to provide solutions that will increase the efficiency and reduce the material cost and lead time of additive manufacturing procedures, thus leading to lighter and stronger parts, having a higher sensitivity to the relevant stimuli.

The 6D printing concept, due to its advantages, is expected to be quickly adopted by the industry which is involved in manufacturing the relevant materials and printing equipment and by other end-users that use AM. The use of 6D printing may be introduced in the same technological and manufacturing SM application field of 3D printing. However, due to the expected higher processing accuracy, new structural and functional capabilities of the proposed method, its application would be more effective in areas where precision is crucial, such as in the aerospace industry, in medical devices and electronics, in operational components for energy applications, etc. More analytically, in the future, 6D printing technology could create disruptive innovation in several fields such as:

- Medical field: Concerning the production of medical parts for prosthetics, orthopedics, or dental implants with better properties and reduced cost. Bones are not flat but have a curved surface, thus the rotation of the bed in order to follow the curve is crucial and, additionally, the created SMs could be used for smart medical implants for complex medical cases [24].

- Constructions: The proposed technique could be easily customized in order to be suitable for the construction of concrete-based structures such as buildings and other infrastructures [39] where the additional printing degrees of freedom would offer a distinct benefit. Used for self-repair and self-adapting systems and products, for example, piping that could dynamically change its diameter and properties in response to the water pressure using smart materials and follow the curves of the pipe using five-axis printing.

- Aerospace engineering: Aimed at the production of curved materials that can reshape according to the temperature.

- Manufacturing industry: For the manufacturing of advanced on-demand products with reduced raw material usage and energy consumption in comparison to previous printing techniques (thus contributing to environmental sustainability and reduced environmental impact).

The proposed AM technique may allow the development of complex products that would be difficult to be manufactured by using standard 3D printing. For example, the 6D printing could permit the production of self-folding furniture that could be printed on flat boards, easily transferred and transported, and then curl up into the final shape after being heated or getting wet. In addition, five-axis movement could allow the creation of objects with curved surfaces that may change properties or geometry according to the weather or other environmental conditions.

\section{Conclusions}

In summary, a novel AM technique is proposed here named 6D printing. The main idea is to combine the $5 \mathrm{D}$ printing concept, which involves the motion of the printing head along with the rotation of the print bed at defined angles, with the 4D printing one, which leads to SMs modified with respect to the time, into a new concept called 6D printing. The realization of the proposed manufacturing procedure is expected to lead to new developments that will increase the efficiency and reduce the material cost and lead time of AM procedures, thus providing lighter and stronger parts, which also have a higher sensitivity to the relevant stimuli. The procedure requires further validation via extensive numerical and experimental investigations and for this reason, some realistic and simple benchmark applications have been also proposed. The rigid establishment of the method only requires the exploration of the SMs recent technological achievements, some previous experience on 3D printing, a five-axis printing machine, and common raw materials. In the near future, relevant research on the optimization of the proposed manufacturing technique is to be announced. 
Author Contributions: Conceptualization, S.K.G. and G.I.G.; methodology, S.K.G. and G.I.G.; formal analysis, S.K.G. and G.I.G.; investigation, S.K.G., G.I.G. and P.A.B.; resources, S.K.G., G.I.G. and P.A.B.; data curation, S.K.G., G.I.G. and P.A.B.; writing-original draft preparation, S.K.G., G.I.G. and P.A.B.; writing - review and editing, S.K.G. and G.I.G.; visualization, S.K.G. and G.I.G.; supervision, S.K.G. and G.I.G. All authors have read and agreed to the published version of the manuscript.

Funding: This research received no external funding.

Institutional Review Board Statement: Not applicable.

Informed Consent Statement: Not applicable.

Conflicts of Interest: The authors declare no conflict of interest.

\section{References}

1. Moon, S.K.; Tan, Y.E.; Hwang, J.; Yoon, Y.J. Application of 3D printing technology for designing light-weight unmanned aerial vehicle wing structures. Int. J. Precis. Eng. Manuf. Green Technol. 2014, 1, 223-228. [CrossRef]

2. Ntouanoglou, K.; Stavropoulos, P.; Mourtzis, D. 4D Printing Prospects for the Aerospace Industry: A critical review. Procedia Manuf. 2018, 18, 120-129. [CrossRef]

3. Manghnani, R. An exploratory study: The impact of additive manufacturing on the automobile industry. Int. J. Curr. Eng. Technol. 2015, 5, 3407-3410.

4. Tay, Y.W.D.; Panda, B.; Paul, S.C.; Noor Mohamed, N.A.; Tan, M.J.; Leong, K.F. 3D printing trends in building and construction industry: A review. Virtual Phys. Prototyp. 2017, 12, 261-276. [CrossRef]

5. Ventola, C.L. Medical applications for 3D printing: Current and projected uses. Pharm. Ther. 2014, $39,704$.

6. Ko, H.; Moon, S.K.; Hwang, J. Design for additive manufacturing in customized products. Int. J. Precis. Eng. Manuf. 2015, 16, 2369-2375. [CrossRef]

7. Astm International. ASTM committee F42 on additive manufacturing technologies, \& ASTM committee F42 on additive manufacturing technologies. Subcommittee F42. 91 on terminology. In Standard Terminology for Additive Manufacturing Technologies; ASTM International: West Conshohocken, PA, USA, 2012.

8. Momeni, F.; Mehdi, M.; Hassani, N.S.; Liu, X.; Ni, J. A review of 4D printing. Mater. Des. 2017, 122, 42-79. [CrossRef]

9. Kačergis, L.; Mitkus, R.; Sinapius, M. Influence of fused deposition modeling process parameters on the transformation of 4D printed morphing structures. Smart Mater. Struct. 2019, 28, 105042. [CrossRef]

10. Noroozi, R.; Bodaghi, M.; Jafari, H.; Zolfagharian, A.; Fotouhi, M. Shape-adaptive metastructures with variable bandgap regions by 4 D printing. Polymers 2020, 12, 519. [CrossRef]

11. Chung, S.; Song, S.E.; Cho, Y.T. Effective software solutions for 4D printing: A review and proposal. Int. J. Precis. Eng. Manuf. Green Technol. 2017, 4, 359-371. [CrossRef]

12. Ge, Q.; Dunn, C.K.; Qi, H.J.; Dunn, M.L. Active origami by 4D printing. Smart Mater. Struct. 2014, 23, 094007. [CrossRef]

13. Pei, E. 4D printing-revolution or fad? Assem. Autom. 2014, 34, 123-127. [CrossRef]

14. Tibbits, S.; Cheung, K. Programmable materials for architectural assembly and automation. Assem. Autom. 2012, 32, 216-225. [CrossRef]

15. Quan, Z.; Wu, A.; Keefe, M.; Qin, X.; Yu, J.; Suhr, J.; Byun, J.-H.; Kim, B.-S.; Chou, T.-W. Additive manufacturing of multidirectional preforms for composites: Opportunities and challenges. Mater. Today 2015, 18, 503-512. [CrossRef]

16. Zolfagharian, A.; Kouzani, A.Z.; Khoo, S.Y.; Moghadam, A.A.A.; Gibson, I.; Kaynak, A. Evolution of 3D printed soft actuators. Sens. Actuators A Phys. 2016, 250, 258-272. [CrossRef]

17. Leist, S.K.; Zhou, J. Current status of $4 \mathrm{D}$ printing technology and the potential of light-reactive smart materials as $4 \mathrm{D}$ printable materials. Virtual Phys. Prototyp. 2016, 11, 249-262. [CrossRef]

18. Wang, Y.; Adokoh, C.K.; Narain, R. Recent development and biomedical applications of self-healing hydrogels. Expert Opin. Drug Deliv. 2018, 15, 77-91. [CrossRef]

19. Li, J.; Li, W.; Huang, W.; Zhang, G.; Sun, R.; Wong, C.P. Fabrication of highly reinforced and compressible graphene/carbon nanotube hybrid foams via a facile self-assembly process for application as strain sensors and beyond. J. Mater. Chem. C 2017, 5, 2723-2730. [CrossRef]

20. Khoo, Z.X.; Teoh, J.E.M.; Liu, Y.; Chua, C.K.; Yang, S.; An, J.; Leong, K.F.; Yeong, W.Y. 3D printing of smart materials: A review on recent progresses in 4D printing. Virtual Phys. Prototyp. 2015, 10, 103-122. [CrossRef]

21. Kwok, T.H.; Wang, C.C.; Deng, D.; Zhang, Y.; Chen, Y. Four-dimensional printing for freeform surfaces: Design optimization of origami and kirigami structures. J. Mech. Des. 2015, 137, 111712. [CrossRef]

22. Zhou, Y.; Huang, W.M.; Kang, S.F.; Wu, X.L.; Lu, H.B.; Fu, J.; Cui, H. From 3D to 4D printing: Approaches and typical applications. J. Mech. Sci. Technol. 2015, 29, 4281-4288. [CrossRef]

23. 3D Printing is So Last Week ... Say Hello to "5D Printing" at Mitsubishi Electric Research Labs! Available online: https: //3dprint.com/139742/mitsubishi-electric-5d-printing/ (accessed on 15 March 2021).

24. Haleem, A.; Javaid, M.; Vaishya, R. 5D printing and its expected applications in Orthopaedics. J. Clin. Orthop. Trauma 2018, 10, 809-810. [CrossRef] 
25. El-Sayegh, S.; Romdhane, L.; Manjikian, S. A critical review of 3D printing in construction: Benefits, challenges, and risks. Arch. Civ. Mech. Eng. 2021, 20, 34. [CrossRef]

26. Ravinder Reddy, P.; Anjani Devi, P. Review on the advancements to additive manufacturing-4D and 5D printing. Int. J. Mech. Prod. Eng. Res. Dev. 2018, 8, 397-402. [CrossRef]

27. Tzou, H.S.; Lee, H.-J.; Arnold, S.M. Smart materials, precision sensors/actuators, smart structures, and structronic systems. Mech Adv. Mater. Struct. 2004, 11,367-393. [CrossRef]

28. Yu, X.; Cheng, H.; Zhang, M.; Zhao, Y.; Qu, L.; Shi, G. Graphene-based smart materials. Nat. Rev. Mater. 2017, 2, 17046. [CrossRef]

29. Kaleem, M.A. Manufacturing graphene based polymer matrix composites (GPMCs) via 3D printing (additive manufacturing): A review. Compos. Theory Pract. 2019, 19, 126-132.

30. Huang, S.H.; Liu, P.; Mokasdar, A.; Hou, L. Additive manufacturing and its societal impact: A literature review. Int. J. Adv. Manuf. Technol. 2013, 67, 1191-1203. [CrossRef]

31. Liu, C.; Qin, H.; Mather, P.T. Review of progress in shape-memory polymers. J. Mater. Chem. 2007, 17, 1543-1558. [CrossRef]

32. Cock, F.; Cuadri, A.A.; García-Morales, M.; Partal, P. Thermal, rheological and microstructural characterisation of commercial biodegradable polyesters. Polym. Test. 2013, 32, 716-723. [CrossRef]

33. Schulz, M.J.; Kelkar, A.D.; Sundaresan, M.J. Nanoengineering of Structural, Functional, and Smart Materials; CRC Press: Boca Raton, FL, USA, 2005; pp. 1-712.

34. Zhang, J.; Koo, B.; Subramanian, N.; Liu, Y.; Chattopadhyay, A. An optimized cross-linked network model to simulate the linear elastic material response of a smart polymer. J. Intell. Mater. Syst. Struct. 2016, 27, 1461-1475. [CrossRef]

35. Mackerle, J. Smart materials and structures: FEM and BEM simulations A bibliography (1997-1999). Finite Elem. Anal. Des. 2001, 37, 71-83. [CrossRef]

36. Cheng, X.; Chen, Y.; Dai, S.; Bilek, M.M.M.; Bao, S.; Ye, L. Bending shape memory behaviours of carbon fibre reinforced polyurethane-type shape memory polymer composites under relatively small deformation: Characterisation and computational simulation. J. Mech. Behav. Biomed. Mater. 2019, 100, 103372. [CrossRef] [PubMed]

37. Mehar, K.; Panda, S.K.; Dewangan, H.C. Multiscale finite element prediction of thermomechanical flexural strength of nanotubereinforced hybrid smart composite panel bonded with SMA fibre. Structures 2020, 28, 2300-2310. [CrossRef]

38. Xu, Y.; Gong, X.; Wan, Q.; Liu, T.; Xuan, S. Magneto-sensitive smart soft material and magnetorheological mechanism. Adv. Mech. 2015, 45, 461-495.

39. Bos, F.; Wolfs, R.; Ahmed, Z.; Salet, T. Additive manufacturing of concrete in construction: Potentials and challenges of 3D concrete printing. Virtual Phys. Prototyp. 2016, 11, 209-225. [CrossRef] 